\title{
A Conceptual Framework of Forest Therapy as an Innovative Health Approach Combined with Local Health Resort Medicine in Alpine Regions to Increase Mental Health and Well-Being
}

\author{
Immich $\mathrm{G}^{1,2,3 *}$ and Schuh $\mathrm{A}^{1,2,3}$ \\ ${ }^{1}$ Chair of Public Health \& Health Services Research at the \\ Institute of Medical Information Processing, Biometry \\ and Epidemiology, Ludwig-Maximilians-University \\ Munich, Germany \\ ${ }^{2}$ Pettenkofer School of Public Health, Ludwig- \\ Maximilians-University Munich, Germany \\ ${ }^{3}$ Competence Center of Forest Medicine and Nature \\ Therapy, Bad Wörishofen, Germany \\ *Corresponding author: Immich G, Chair of Public \\ Health \& Health Services Research at the Institute \\ of Medical Information Processing, Biometry and \\ Epidemiology, Ludwig-Maximilians-University Munich, \\ Germany
}

Received: May 05, 2021; Accepted: J une 12, 2021; Published: J une 19, 2021

\begin{abstract}
Introduction: There has been a constant increase in mental health disorders in Western industrialized nations, and the current Covid 19 pandemic is increasingly exacerbating the problem. The health resorts in Germany are well equipped to improve mental, emotional and physical health with their local remedies and procedures to improve the individual health status.
\end{abstract}

Method: The available alpine health resort procedures/interventions as well as the novel forest therapy with their various effects are described in order to develop a novel health resort concept for the treatment of mental-health disorders and well-being.

Result: Based on the principles of health resort medicine (HRM) and the available alpine interventions, a three-week treatment concept has been developed. Different procedures such as climatotherapy, balneotherapy, forest therapy \& nature connection, mindfulness practice and physiotherapy have been combined in a healthy manner. Alpine health resorts are particularly well suited because of their excellent health-promoting climate factors.

Conclusion: The novel combination of HRM with forest therapy will lead to stress reduction and an increase in mental health and general well-being. This new approach shows promising benefits for future health resort treatments. Studies on this new approach are needed to confirm the effectiveness of the conceptual framework.

Keywords: Health resort medicine; Forest therapy; Climatotherapy; Cure regime; Prevention; Mental health; Well-being

\section{Introduction}

The mental health crisis is worldwide increasing, especially in cities. Prior to covid-19 pandemic, $12 \%$ of the German population were already seriously mentally ill and $28 \%$ of the population already experienced mild mental illnesses [1], 34\% of the reasons for occupational disability were mental illness with an average duration of a sick note of 33.7 days. Another survey classifies one in six Europeans as mentally ill [2] with rising trend. These data indicate that mental and behavioral disorders represent a serious public health issue which will be accelerates and worsens by the current covid-19 pandemic worldwide [3]. On the other hand, health resorts are special places that are conducive to good health [4]. They are located in high mountain areas, on the shore and in low mountain areas and mainly situated in a preferred quiet natural environment with special climatic conditions that are beneficial to health. The traditional Health Resort Medicine (HRM) is well known for its wealth of experience and sound scientific evidence of the effectiveness of its local resources [5]. New health resort concepts for future medical topics have already been conceived, evaluated and implemented in different German health resorts which demonstrate sustainable results in the improvement of various diseases [6-8]. HRM offers different therapeutic options for the treatment of gastrointestinal, circulatory, respiratory, bone and joint, psychosomatic and mental health diseases, and skin and soft tissue disorders. This paper will highlight the positive effects of HRM in alpine areas and highlight the benefit of forest therapy as a new additive therapeutical approach.

\section{Materials and Methods}

\section{Health resort medicine}

Health Resort Medicine (HRM) can be described as a field of medicine with long-lasting tradition worldwide [4]. HRM includes different interventions and methods for health promotion, prevention, therapy and rehabilitation based on its local natural resources. The health-promoting health resort atmosphere is very important for the recovery of the patients. The quiet tranquil and well-structured health resort is mostly surrounded by nature and offers relief from urban noise, heat and air pollutants. Additional to the health-promoting environment, the different interventions and methods have been structured chronobiologically in a 1-3 week cure regime [6-8]. Each therapeutic intervention will be scheduled in a chronobiological order at the optimal time of day to increase the success of the 
intervention. For example, psychoeducation should be planned for the later morning, as concentration and attention to cognitive tasks are highest [9]. Hot applications such as sauna should not be carried out in the evening, as they impede the chronobiologically controlled temperature reduction of the body. Another HRM principle is the daily alternation of load and rest in order to increase the ability to recover. This should prevent physical overstrain during recovery [10]

\section{Local natural resources of an (alpine) health resort: its specific climate}

There are a variety of local health resort resources in mountain areas available such as thermal water, gases or specific climatic conditions. The most important natural "remedy" in alpine health resort is the mountain climate itself. The high mountain climate is predominantly irritant intensive, but is also characterized by the relieving effect of the climate factors high air purity and allergen reduction [11]. With increasing altitude, solar radiation and wind speed increase, while air pressure, oxygen partial pressure, water vapour pressure and air temperature decrease. The high mountain climate is particularly advantageous for people with allergies, as the short vegetation phase and the altitude significantly reduces pollen and mould and, from 1600 above sea level, house dust mites are no longer present [12]. The mountain climate has particularly pure, clean air, which is enhanced by the abundance of forests. This affects positively the relief of the respiratory tract due to the absence of anthropogenic pollutants, which is important for the prevention and therapy of lung diseases [13].

In the high mountains, there are also particularly high UVB radiation intensities all year round, which can be used to promote health and therapeutically to stimulate vitamin D synthesis in the skin [13]. This procedure is called heliotherapy and is performed without cosmetic skin protection in order not to limit the biopositive effects of UVB radiation. Therefore, it is important to ensure that the radiation doses of the individual heliotherapeutic units are applied in suberythematous doses. In addition to heliotherapy, the high light intensities can also be used therapeutically for the readjustment of the circadian rhythm or for the therapy of the seasonal affective disorder, e.g. in the case of derhythmization of the inner clock through a constant indoor lifestyle.

As the altitude increases, the air temperature, the oxygen content of the air and the air humidity decrease. These climatic factors will be used when conducting the climatic terrain cure which is an endurance capacity training under cool skin temperature conditions [11]. As a result, sweat can evaporate more easily during physical activity and the thermoregulation system is relieved which is beneficial for patients suffering on atopic or non-allergic skin diseases.

In summary, the clean, cool air in combination with the alpine altitude and the abundance of forests are particularly favourable climatic health factors.

\section{Interventions in health resort medicine}

The core HRM interventions consists of (1) Balneotherapy (usage of natural mineral water/medical peloids/natural gases for bathing, drinking or inhalation), (2) Hydrotherapy (application of plain water), and (3) Climatotherapy (therapeutic usage of climatic factors) [14]. Rehabilitation strategies in HRM may include physiotherapeutic methods such as therapeutic massage, water massage, numerous forms of exercise such as water exercise, breathing, balance, and muscle-strengthening and endurance exercises, health education in form of psychoeducational seminars, psychological interventions, and other complementary treatments [15].

\section{Forest therapy in health resort medicine}

"Forest therapy" is derived from the Japanese original "ShinrinYoku" which literally means "immersion in the atmosphere of the forest" [16]. Because different terms are used internationally, we define "forest bathing" as the health-promoting and preventive use of the forest, whereas forest therapy describes the therapeutic application of forest visits. A large number of studies clearly prove the positive effects of forest visits on the psyche and mental well-being $[17,18]$. Positive emotional regulation by reduction of anxiety, anger, fatigue and sadness, increase of attentiveness and concentration. In addition to the mental improvement, the special forest climate with its cool and clean air and high humidity relieves the respiratory system [11]. Also, microbes and BVOCs show an influence on the human immune system $[19,20]$. In addition, visits to nature promote physical activity [21].

Besides the classical health resort medicine, forest therapy qualifies as a new innovative approach in HRM [22]. Forest therapy can be combined in a special HRM regime with mindfulness practice, nature connectedness, and health resorts elements like climatotherapy and hydrotherapy. The interventions are based on the scientific knowledge of medical climatology, naturopathic medicine, recreation and stress research as well as psychological and mindfulness knowledge. The forest-based program should be guided by a specially trained forest health trainers/forest therapy guide/forest therapist. Depending on the target group, different concepts of health promotion, prevention or therapy can be carried out in the natural environment of an alpine health resort [14].

\section{Results}

The focus in the therapy of mental health disorders is the reduction of existing symptoms (emotionally and cognitive recuperation) as well as physical regeneration, and the improvement of sleep quality, everyday functions and participation which will be initiated by a conceptional framework of a multimodal 3 week cure program.

After arrival at the health resort, a medical admission examination including pneumological, internal and psychological diagnostics has to be conducted. Depending on the severity of the symptoms and the rehabilitation goals, individual therapy planning has to be carried out. The following innovative concept of a 3 week rehabilitation program is designed for patients with mental health disorders and reduced general well-being. This therapeutic cure concept has now been compiled for the first time as a multimodal, health resort rehabilitation programme based on the principles of health resort medicine and its local health resort resource.

The new concept of a 3-week rehabilitation programme consists of a variety of different interventions that complement each other in their effects: 1) Specific health resort resources and its treatment (climatotherapy, balneotherapy); 2) Physiotherapy and respiratory therapy (inhalations); 3) Physical and endurance training, strength and balance training (e.g. climatotherapy); 4) Forest therapy for 
Table 1: Structured cure plan for a 3 week rehabilitation program for mental health disorders in (apine) health resorts. The activity level is described in A-days (rest) and b-days (load).

\begin{tabular}{|c|c|c|c|c|c|}
\hline \multicolumn{6}{|c|}{$1^{\text {st }}$ Week - Low Intensity } \\
\hline \multirow[t]{2}{*}{ Time } & Monday & Tuesday & Wednesday & Thursday & Friday \\
\hline & Day A (rest) & Day B (load) & Day A (rest) & Day B (load) & Day A (rest) \\
\hline $9-10 \mathrm{am}$ & Breathing exercises & Mindful walking & Breathing exercises & Mindful walking & Breathing exercises \\
\hline $10: 30-12 \mathrm{am}$ & Psychoeducation 1 & Psychoeducation 2 & Climatotherapy: Heliotherapy & Psychoeducation 3 & Psychoeducation 4 \\
\hline $12-2 \mathrm{pm}$ & $\begin{array}{c}\text { Lunch break with power } \\
\text { napping }\end{array}$ & $\begin{array}{c}\text { Lunch break with power } \\
\text { napping }\end{array}$ & $\begin{array}{l}\text { Lunch break with power } \\
\text { napping }\end{array}$ & $\begin{array}{c}\text { Lunch break with power } \\
\text { napping }\end{array}$ & $\begin{array}{c}\text { Lunch break with power } \\
\text { napping }\end{array}$ \\
\hline $2-4 \mathrm{pm}$ & Forest therapy & Hot water immersion & $\begin{array}{l}\text { Climatotherapy: Fresh air } \\
\text { rest cure }\end{array}$ & Hot water immersion & Forest therapy \\
\hline $4-5 \mathrm{pm}$ & Inhalation & Physiotherapy & Inhalation & Physiotherapy & Inhalation \\
\hline \multicolumn{6}{|c|}{$2^{\text {nd }}$ Week - Normal Intensity } \\
\hline \multirow[t]{2}{*}{ Time } & Monday & Tuesday & Wednesday & Thursday & Friday \\
\hline & Day B (load) & Day A (rest) & Day B (load) & Day A (rest) & Day B (load) \\
\hline $9-10$ am & Mindful walking & Breathing exercises & Balance training & $\begin{array}{l}\text { Climatotherapy: Fresh air } \\
\text { rest cure }\end{array}$ & Mindful walking \\
\hline $10: 30-12 \mathrm{am}$ & Psychoeducation 5 & Psychoeducation 6 & $\begin{array}{l}\text { Climatotherapy: Fresh air } \\
\text { rest cure }\end{array}$ & Psychoeducation 7 & Psychoeducation 8 \\
\hline $12-2 \mathrm{pm}$ & $\begin{array}{l}\text { Lunch break with power } \\
\text { napping }\end{array}$ & $\begin{array}{l}\text { Lunch break with power } \\
\text { napping }\end{array}$ & $\begin{array}{l}\text { Lunch break with power } \\
\text { napping }\end{array}$ & $\begin{array}{c}\text { Lunch break with power } \\
\text { napping }\end{array}$ & $\begin{array}{c}\text { Lunch break with power } \\
\text { napping }\end{array}$ \\
\hline $2-4 \mathrm{pm}$ & Hot water immersion & Forest therapy & Climatotherapy: Terrain cure & Forest therapy & Hot water immersion \\
\hline $4-5 \mathrm{pm}$ & Physiotherapy & Inhalations & Physiotherapy & Inhalations & Physiotherapy \\
\hline \multicolumn{6}{|c|}{$3^{\text {rd }}$ Week - Normal to Increased Intensity } \\
\hline \multirow[t]{2}{*}{ Time } & Monday & Tuesday & Wednesday & Thursday & Friday \\
\hline & Day B (load) & Day A (rest) & Day B (load) & Day A (rest) & Day B (load) \\
\hline $9-10 \mathrm{am}$ & Balance training & Breathing exercises & Mindful walking & Breathing exercises & Mindful walking \\
\hline $10: 30-12 \mathrm{am}$ & Psychoeducation 9 & $\begin{array}{l}\text { Climatotherapy: } \\
\text { Heliotherapy }\end{array}$ & Climatotherapy: Terrain cure & Psychoeducation 10 & Climatotherapy: Terrain cure \\
\hline $12-2 \mathrm{pm}$ & $\begin{array}{c}\text { Lunch break with power } \\
\text { napping }\end{array}$ & $\begin{array}{c}\text { Lunch break with power } \\
\text { napping }\end{array}$ & Climatotherapy: Terrain cure & $\begin{array}{c}\text { Lunch break with power } \\
\text { napping }\end{array}$ & $\begin{array}{c}\text { Lunch break with power } \\
\text { napping }\end{array}$ \\
\hline $2-4 \mathrm{pm}$ & Hot water immersion & Forest therapy & Climatotherapy: Terrain cure & Forest therapy & $\begin{array}{l}\text { Program evaluation, } \\
\text { feedback }\end{array}$ \\
\hline $4-5 \mathrm{pm}$ & Physiotherapy & Inhalations & Physiotherapy & Inhalations & Farewell and departure \\
\hline
\end{tabular}

mental and emotional well-being and cognitive restoration (forestbased mindfulness practice, connection to nature, climatotherapy); 5) Psychoeducational trainings to impart knowledge about the disease and its effects, stress management training, introduction to mindfulness practice, teaching of naturopathic self-treatment forms as well as learning coping strategies on an individual level in order to better deal with the burden of disease now and in the future when back home. Additioanlly, if necessary, psychpsychological counseling for patients with post-traumatic stress disorder, depression and anxiety disorders like persistent fears are recommended.

The conceptual framework of a 3-week therapy plan for increasing mental health and well-being in an alpine health resort is chronobiologially structured and a balanced alternation of stress and relief (change in the level of demand) as well as activation and deactivation (change in the level of activation) is necessary (Table 1) [10].

The first week of the rehabilitation program deals with activates on a low intensity level, whereas during the second and third week the length and/or intensity will be increased slightly dependent on the patients conditions. An overload of activity needs to be avoided.

The specific goals in the rehabilitation regime of health complaints are 1) The improvement of psychological and cognitive status; 2) Improvement of physical performance, balance and fitness; 3) Teaching and training of mindfulness practice; 4) Reduction of physical symptoms based on emotional regulation; 5) Developing confidence in physical resilience through targeted training in mindfulness, climatotherapy, and forest therapy.

Specific objectives in mental health treatment will be: 1) To manage the disease and promote quality of life; 2) Knowledge of key warning signs of exhaustion; 3) Increase knowledge in dealing with stress and stressful situations (stress management); 4) Reduction of negative emotions such as depression, anxiety; 5) Improvement of self-perception and self-esteem; 6) Maintain a healthy balance and equilibrium; 7) Learning strategies for coping with disease; 8) Specific health resort resources to maintain a healthy state; 9) Strategies to overcome loneliness and increase social participation; 10) Teaching about digital devises and useful application. All of these different objects should be addressed in the psychoeducational seminar.

All of these different topics can be carried out within a multimodal interdisciplinary rehabilitation program in a (alpine) health resort to increase the patient well-being and to improve the mental state.

\section{Discussion}

Health resort medicine is established throughout Europe and 
recognized as a preventive, therapeutic and rehabilitative health service, but is often assessed as not very effective. However, different randomized controlled trials demonstrate a cost-effective and sustainable treatment option of HRM with less side effects [6-8]. A systematic review demonstrated the evidence of climatotherapeutic interventions in the mountain health resorts [23]. Also Kubincová et al. (2018) have proven in a mountain environment, that rehabilitation services will be effective in COPD and chronic bronchitis [24].

The benefit of the lower air temperature will gain more and more importance in the light of the coming decades: The rising global temperatures will lead to an increase in heat-related diseases and deaths, especially in cities [25]. High temperatures in summer are problematic and conducive to disease, as the night-time cooling of air below $25^{\circ} \mathrm{C}$ is hindered by urban heat islands. However, people need a lower night-time temperature for recovery/regeneration and to stay healthy. This need is chronobiologically controlled, as the body wants to warm up in the evening, i.e. reduce the excess core body temperature. If this is not possible, there is an increase in cardiovascular and respiratory diseases, heat-related exhaustion, heat stroke, embolisms, and even liver and kidney failure [26]. Old people and children in particular have a limited thermoregulatory capacity and suffer above all from high temperatures [27]. Therefore, especially persistent cooler night-time and daytime summer temperatures in alpine regions are particularly beneficial for health maintenance and the thermoregulatory system.

Good air quality is an important health request of every health resort. The surrounding green environment and especially trees absorb and store air pollutants to a considerable extent, thus improving the air quality in the health resort [5]. It is proven, that air pollutants increase airways diseases and causing earlier deaths worldwide [27]. Therefore, alpine regions show a strong potential of relief for patients with airway and lung diseases.

Recent research also shows that visits to nature have positive health-promoting and therapeutic effects on mood, cognition, and psychological well-being, which have been described in various landscape and evolutionary theories: biophilia hypothesis [28], stress reduction theory [29], attention restoration theory [30], and prospect and refuge theory [31]. A large number of studies prove the positive effects of nature visits on mental recovery and well-being [32]. The frequency of visits to nature seems to be an important factor in achieving sustainable effects. Latest research recommend at least 120 minutes visit a forest/nature environment a week for positive impact [33]. Listening to nature sounds during a forest-based intervention will lead to stress reduction and positive regulation of the mood and emotional well-being [34]. Besides strengthening of memory and concentration skills, mental health status will be improved and anxiety and depressive moods decreased by the current cure regime based on sufficient data [35].

Mental illness is often associated with sleep problems such as insomnia. Morita et al. (2011) demonstrate that forest walks promotes a healthy, restful sleep [36]. Therefore, nature-based programs in a cure regime seem very appropriate to ecotherapy tourism [37]. This clearly speaks in favour of combining health resort interventions with mindfulness forest therapy settings [38]. Especially patients suffering on dementia benefits in particular from the improved quality of sleep due to natural "intervention" outdoors [39].

An increasingly important research topic is the relationship between intestinal colonization and brain functions [40]. Studies have shown that WEIRD societies (Western, educated, industrialized, rich, democratic) are characterized by the removal of germs and bacteria through antibiotics, disinfection, birth by caesarean section [41]. This behaviour will lead to a dysfunctional gut-brain-axis. Visits to nature can improve the natural microbiome balance in the intestine which can reduce silent inflammations [42]. For example, natural soil contains useful germs and bacteria that have a positive effect on the intestinal-brain axis. The latest research results show that direct contact with soil or inhalation of forest air can lead to an improved state of mental health [43]. For example, allergic predisposition can be reduced through contact with nature in early childhood [44] and the activity of the human microbiome can be promoted [45]. Due to this new insights, nature contact seems to be very important in the prevention and therapy of different mental health conditions [46]. Therefore, based on the literature it is highly recommended, to add different nature-based intervention to deepen the personal nature connection $[47,48]$.

Forst bathing and forest therapy will strengthen the nature connectedness by increasing mindfulness and awareness [49]. When people experience a strong affinity with nature, more positive emotions are triggered: these people are happier, significantly more vital and have a higher level of life satisfaction, which is expressed in an improved general sense of well-being [46]. Furthermore, this emotional closeness to nature supports a stronger environmentally conscious behaviour [50]. Mountain areas are often covered with different types of forests which can be easily used for nature immersions and climatotherapeutic interventions for mental restoration and general well-begging as well as for therapeutic interventions.

Forest therapy can be used therapeutically in mental health disorders such as exhaustion, depression, anxiety disorders and trauma sequelae (post-traumatic stress response) [51]. The healthprotective effect of a forest is proven by epidemiological studies: living near forests promotes cardiovascular health and can reduce the incidence of certain cancers [52]. Similarly, being close to nature seems to be a positive factor for higher life expectancy [53]. A promising holistic approach includes the concept of closeness to nature, which describes the emotional connection to nature, its conservation efforts and environmental behaviour. Initial studies suggest that when people feel more connected with and in nature, this leads to a general improvement in well-being [49].

Cervinka et al. (2011) demonstrated on 550 people that people who are more in touch with nature have a stronger sense of meaning in their lives [47]. The people describe their lives as fulfilling and joyful, experience a high level of self-acceptance and to others and are highly self-esteemed. In contrast, attributes such as powerlessness or helplessness, and fear or displeasure are largely absent. Furthermore, nature-loving people are socially strongly networked and feel a high level of life satisfaction and well-being. Thus the fact of a high degree of closeness to nature could be interpreted as a positive personality aspect and therefore as an individual health resource. Forest therapy programs combined with climatotherapy and Kneipptherapy will 
take up this topic and want to counteract daily challenges, stressors and the one-sided indoor life by guided sensory and emotional forest experiences. Richardson et al. (2018) also name the connection to nature as an antipole to stress, which generates a certain kind of stronger resistance and can thus represent a form of resilience [54].

Mindfulness practice such as MBSR is well proven and integrated into medical care for a long time as are other body-mind techniques such as Tai Chi, Qi-gong and relaxation techniques or progressive muscle relaxation, and can be easily carried out in nature. Mindfulness practice in nature will strengthen the mental health status and increase the general well-being [49]. Thus, in addition to education and income, guiding a deep connection to nature could be interpreted as an important element for general and emotional well-being and could be regarded as a natural lifestyle intervention, as health programmes with nature-related aspects could be better accepted and thus easier to implement [55]. Forest therapy as a nature-based intervention is also an inexpensive treatment option.

The use of natural medicinal resources in the form of treatments in health resort medicine centers, combined with the healing properties of the climate, contributes not only to the reduction of treatment time for many diseases but also to improvement of therapy's results [22] The health beneficial as well as therapeutic effects of forest therapy could be synergistically combined with other spa treatments as a new innovative nature-based approach in classical HRM. Health resort studies in diverse regions with different forest areas must be carried out to prove the conceptual approach and to approve its effectiveness.

\section{Conclusions}

The cure regime in a health resort is an interdisciplinary approach where multi-professional team members are working together for the optimal patient's health outcome. The novel combination of classical health resort medicine with various forms of forest therapy and nature connection interventions will to lead to stress reduction and an increase in mental, cognitive and physical health and general well-being. Alpine health resorts are particularly well suited because of their excellent health-promoting climate factors as well as their richness of forest environments.

This new approach shows promising benefits for future health resort treatments. Especially due to the dramatically increase of mental health disorders caused by covid-19 pandemic this naturebased intervention in health resorts is very much recommended. Studies on this new approach are needed to confirm the effectiveness of the conceptual framework.

\section{References}

1. AXA Germany. Health Report 2020 - Die unsichtbare dritte Welle die Psyche trifft. Wie Covid-19 die Psyche trifft. [Mental Health Report 2020 - The invisible third wave hits the psyche. How Covid-19 hits the psyche].

2. OECD/EU. Health at a Glance: Europe 2018: State of Health in the EU Cycle OECD Publishing; Paris, Brussel; European Union. 2018.

3. Statista Research Department. COVID-19 impact on mental health - statistics \& facts. Statista Dossier. 2020.

4. De Vierville JP. Spa Culture: A brief history of spa \& health resort medicine in civilization. In: Health resort medicine in $2^{\text {nd }}$ millennium; Eds. Bender $\mathrm{T}$, Pratzel H. ISMH Publishing, Törpin, Germany. 2004: 49-56.

5. Nowak DJ, Hirabayashi S, Bodine A, Greenfield E. Tree and forest effects on air quality and human health in the United States. Environ Pollut. 2014; 193: 119-129.

6. Stier-Jarmer M, Kus S, Frisch D, Sabariego C, Schuh A. Health resort medicine in non-musculoskeletal disorders: is there evidence of its effectiveness? Int J Biometeorol. 2015; 59: 1523-1544.

7. Stier-Jarmer M, Frisch D, Oberhauser C, Berberich G, Schuh A. The effectiveness of a stress reduction and burnout prevention program. Dtsch Arztebl Int. 2016; 113: 781-788.

8. Ehegartner V, Frisch D, Kirschneck M, Schuh A, Kus S. Wirksamkeit eines Präventionsprogrammes mit Auffrischungstagen für Pflegekräfte PFLEGEprevent. [Effectiveness of a prevention programme with refresher days for nursing staff - PFLEGEprevent]. Das Gesundheitswesen. 2018; 80: 791-791.

9. Blatter K, Cajochen C. Circadian rthythms in cognitive performance: methodological constraints, protocols, theoretical unterpinnings. Physiol \& Behavior. 2007; 90: 196-208.

10. Allmer $H$. Recreation and health: Foundations, results and measures. Hogrefe Publisher, Göttingen, Germany. 1996.

11. Schuh A. Klima- und Thalassotherapie [Climatotherapy and Thalassotherapy]. Hippokrates Publisher: Stuttgart, Germany. 2004.

12. Grafetstätter C, Prossegger J, Braunschmid H, Sanovic R, Hahne P, Pichler C, et al. No Concentration Decrease of House Dust Mite Allergens with Rising Altitude in Alpine Regions. Allergy, Asthma Immunol Res. 2016; 8: 312-318.

13. Schuh A. Die Evidence der Klima- und Thalassotherapie. [The evidence of climatotherapy and thalassotherapy]. Schweiz. Zschr. GanzheitsMedizin. 2009; 21: 96-104.

14. Gutenbrunner C, Bender T, Cantista $P$, Karagülle $Z$. A proposal for a worldwide definition of health resort medicine; balneology; medical hydrology and climatology. Int J Biometeorol. 2010; 54: 495-507.

15. Maitre J, Guinhouya B, Darrieutort N, Paillard T. Physical education in a thermal spa resort to maintain an active lifestyle at home: A one-year selfcontrolled follow-up pilot study. Evid Based Complement Alternat Med. 2017; 1058419.

16. Lee JY, Lee DC. Cardiac and pulmonary benefits of forest walking versus city walking in elderly women: A randomised; controlled; open-label trial. Eur J Integr Med. 2014; 6: 5-11.

17. Bowler DE, Buyung-Ali LM, Knight TM, Pullin AS. A systematic review of evidence for the added benefits to health of exposure to natural environments. BMC Public Health. 2010; 10: 456.

18. Hansen MM, Jones R, Tocchini K. Shinrin-Yoku (Forest Bathing) and nature therapy: A state-of-the-art review. Int J Environ Res Public Health. 2017; 14: 851.

19. Lowry CA, Hollis JH, de Vries A, Pan B, Brunet LR, Hunt JR, et al. Identification of an immune-responsive mesolimbocortical serotonergic system: potential role in regulation of emotional behavior. Neurosci. 2007; 146: 756-772.

20. Li Q. Effect of forest bathing trips on human immune function. Envirom Health Prevent Med. 2009; 15: 9-17.

21. Kaczynski AT, Henderson KA. Environmental correlates of physical activity: A review of evidence about parks and recreation. Leisure Sci. 2007; 29: 315354.

22. Ziemska J, Szynal T, Mazańska M, Solecka J. Natural medicinal resources and their therapeutic applications. Rocz Panst Zakl Hig. 2019; 70: 407-413.

23. Schuh A, Nowak D. Klimatherapie im Hochgebirge und im Meeresklima. Evidente Akut- und Langzeiteffekte-ein qualitativer Review [Evidence-based acute and long-lasting effects of climatotherapy in moderate altitudes and on the seaside]. Dtsch Med Wochenschr. 2011; 136: 135-139.

24. Kubincová $A$, Takáč $P$, Kendrová $L$, Joppa $P$, Mikuláková $W$. The effect of pulmonary rehabilitation in mountain environment on exercise capacity and quality of life in patients with Chronic Obstructive Pulmonary disease (COPD) and chronic bronchitis. Med Sci Monit. 2018; 24: 6375-6386. 
25. Voorhees AS, Fann N, Fulcher C, Dolwick P, Hubbell B, Bierwagen B, et al Climate change-related temperature impacts on warm season heat mortality. Environ Sci Technol. 2011; 45: 1450-1457.

26. Kleerekoper L, van Esch M, Salcedo T. How to make a city climate-proof; addressing the urban heat island effect. Resourc Conserv Recycl. 2012; 64 30-38.

27. World Health Organization. Urban green spaces and health. WHO Regional Office for Europe, Copenhagen, Denmark. 2016.

28. Wilson EO. Biophilia. Harvard University Press, Cambridge, Great Britain 1984

29. Kaplan S. The restorative benefits of nature: toward an integrative framework. J Environ Psychol. 1995; 15: 169-182.

30. Ulrich RS. Visual landscapes and psychological well-being. Landsc Res. 1979; 4: 17-23.

31. Appleton J. The experience of landscape. John Wiley and Son Publishing New York, NY. 1975

32. Doimo I, Masiero M, Gatt P. Forest and Wellbeing: Bridging Medical and Forest Research for Effective Forest-Based Initiatives. Forests. 2020; 11 791.

33. White MP, Alcock I, Grellier J, Wheeler BW, Hartig T, Warber SL, et al Spending at least 120 minutes a week in nature is associated with good health and wellbeing. Sci Rep. 2019; 9: 7730.

34. Cerwén G, Pedersen E, Pálsdóttir AM. The role of soundscape in nature based rehabilitation: A patient perspective. Int J Environ Res Public Health 2016; 13: 1229.

35. Schuh A, Immich G. Waldtherapie. Das Potenzial des Waldes für die Gesundheit. [Forest therapy-the potential of forests for health]. Springer Nature Publisher: Berlin, Heidelberg, Germany. 2019

36. Morita E, Imai M, Okawa M, Miyaura T, Miyazaki S. A before and afte comparison of the effects of forest walking on the sleep of a community-based sample of people with sleep complaints. Biopsychosoc Med. 2011; 5: 13

37. Ohe Y. Evaluating the relaxation effects of emerging forest-therapy tourism: A multidisciplinary approach. Tour Manag. 2017; 62: 322-334.

38. Ensinger K. Mindfulness; natural environment experience and recovery experiences. J Environ Psychol. 2016; 20: 95-111.

39. Orr N, Wagstaffe A, Briscoe S, Garside R. How do older people describe their sensory experiences of the natural world? A systematic review of the qualitative evidence. Brit Med J Geriat. 2016; 16: 116.

40. Valles-Colomer M, Falony G, Darzi Y, Tigchelaar EF, Wang J, Tito RY, et al. The neuroactive potential of the human gut microbiota in quality of life and depression. Nat Microbiol. 2019; 4: 623-632.

41. Flandroy L, Poutahidis T, Berg G, Clarke G, Dao MC, Decaestecker E, et al. The impact of human activities and lifestyles on the interlinked microbiota and health of humans and of ecosystems. Sci total Environ. 2018; 15: 1018-1038.
42. Bird We, Epel E, Ickovics JR, van den Bosch M. Unifying mechanisms: nature deficiency, chronic stress, and inflammation. In: Oxford Textbook of Nature and Public Health; Eds. Van den Bosch und Bird. Oxford University Press: Oxford, Great Britain. 2018: 40-48.

43. Frank MG, Fonken LK, Dolzani SD, Annis JL, Siebler PH, Schmidt D, et al. Immunization with Mycobacterium vaccae induces an anti-inflammatory milieu in the CNS: Attenuation of stress-induced microglial priming; alarmins and anxiety-like behavior. Brain Behav Immun. 2018; 73: 352-363.

44. Von Mutius E. Die Rolle des Umweltmikrobioms in der Asthma-und Allergieentstehung. [The role of the environmental microbiome in astham and allergy development]. In: Die unbekannte Welt der Mikrobiome [The unknown world of microbiomes]; Bayerische Akademie der Wissenschaften (Ed); Dr. Friedrich Pfeil Publishing, Munich, Germany. 2019; 47: 121-128.

45. Prescott SL, Millstein RA, Katzman MA, Logan AC. Biodiversity; the human microbiome and mental health: Moving toward a new clinical ecology for the $21^{\text {st }}$ century? Int J Biodiv. 2016.

46. Capaldi CA, Dopko RL, Zelenski JM. The relationship between nature connectedness and happiness: a meta-analysis. Front Psychol. 2014; 5: 976.

47. Cervinka R, Röderer K, Hefler E. Are nature lovers happy? On various indicators of well-being and connectedness to nature. J Health Psychol. 2011; 17: 379-388

48. Kuo M. How might contact with nature promote human health? Promising mechanisms and a possible central pathway. Front Psychol. 2015; 6: 1093

49. Howell AJ, Dopko RL, Passmore HA, Buro K. Nature connectedness: Associations with well-being and mindfulness. Personal Indiv Difference. 2011; 51: 166-171.

50. Zelenski JM, Nisbet EK. Happiness and feeling connected: The distinct role of nature relatedness. Environ Behav. 2012; 46: 3-23.

51. Bielinis E, Jaroszewska A, Lukowski A, Takayama N. The effects of a forest therapy programme on mental hospital patients with affective and psychotic Disorders. Int J Environ Res Public Health. 2020; 118.

52. Li Q, Kobayashi M, Kawada T. Effect of forest coverage on standardized mortality ratios of cancers in Japan. In: Forest Medicine, Ed. Li Q. Nova Science Publishers; New York, United Nations of America. 2012: 219-229.

53. Ji JS, Zhu A, Bai C, Wu C-D, Yan L, Tang S, et al. Residential greenness and mortality in oldest-old women and men in China: a longitudinal cohort study. Lancet Planet Health. 2019; 3: E17-E25.

54. Richardson M, McEwan $\mathrm{K}, 30$ days wild and the relationships between engagement with nature's beauty; nature connectedness and well-being. Front Psychol. 2018; 9: 1500

55. Haluza D, Simic S, Höltge J, Cervinka R, Moshammer H. Connectedness to nature and public (skin) health perspectives: results of a representative; population-based survey among Austrian residents. Int J Environ Res Public Health. 2014; 11: 1176-1191. 